\title{
Students' perspectives of an EAP pathway program.
}

\begin{abstract}
Increasing numbers of overseas students are applying to study at universities in Australia. Many students who meet all of the university's academic entry requirements except English language proficiency are offered pathway programs which prepare them for their tertiary studies. To date, much of the research relating to international students focuses on their progress in tertiary, rather than pathway programs, and little is known about the students' own impressions. One such program in Western Australia was the subject of a two-phase study which was carried out through interviews with thirteen students from a range of cultural and linguistic backgrounds, in order to find out what perceptions they had of its effectiveness. The participants noted that they had benefited from taking this program, as it had provided them with a good transition to studying in Australia, but a number of obstacles still had to be overcome. The results also reveal that readiness to study in a tertiary institution goes well beyond the achievement of an English language proficiency score for entry. Modifications to the program are recommended.
\end{abstract}

Keywords: EAP; pathway program; intercultural communication; international students; English language proficiency; cultural and linguistic background.

\section{Introduction}

Over the last twenty years or so, there has been a phenomenal growth in the number of international students seeking places in tertiary institutions in English-speaking countries, and this demand is set to continue. In Australia,'overseas student enrolments in universities have recorded their highest growth since the second half of 2006, defying the high cost of an Australian education driven by the dollar's exchange rate' (Healy, 2008). This increase has brought about a range of challenges, such as the integration of many diverse cultures and language backgrounds into university life. It also involves catering for the diverse nature of the student body, and the provision of an international focus in all courses, both at curriculum and policy levels. In addition to meeting academic criteria, prospective students need to provide proof of English language proficiency, usually by means of a minimum cut-off score on the International English Language Testing System (IELTS) test. This score is normally determined by the receiving institution or department. As an alternative, many universities now offer pretertiary programmes as pathways to tertiary study. One such example is a university in Western Australia, which offers the English Language Bridging Course (ELBC), which prepares students from non-English speaking backgrounds for both undergraduate and postgraduate studies. It is designed for students who meet all other university academic entry requirements, but who have failed to reach the cut-off scores (usually 6.0 overall on IELTS) required to demonstrate English language proficiency for 'direct entry' into tertiary courses. Such students who have achieved a minimum score of 5.0 overall on IELTS, are offered a place on their chosen tertiary course, pending successful completion of the semester-long ELBC and achieving an exit score that has 
been pre-determined by the receiving department. They are not required to take the IELTS test again.

A two-phase study was carried out to evaluate the degree to which this university is meeting the needs and expectations of international students, from the students' own perspective. The first phase was undertaken upon completion of the ELBC, and aimed to find out what perceptions the students had of their readiness to study in Australia. The second phase was undertaken after the same students had completed at least one full semester in their tertiary course. In particular, the role and scope of the ELBC in preparing its students for their tertiary studies was examined post-facto. Students whose first language is other than English are referred to here as non-native (English) speakers (NNS), while those whose first language is English are referred to as native speakers (NS).

\section{English language skills and academic preparation}

The relationship between English language proficiency and successful study in Australia has been widely discussed in the media and in universities (Birrell, 2006; Arkoudis, 2008). Increasing emphasis is being placed on the need to not only demonstrate the appropriate language skills to successfully engage in a tertiary degree, but also to be deemed sufficiently competent to secure employment upon graduation. While there is a minimum English language proficiency level below which students could be at risk of failing, the achievement of a minimum score on a proficiency test is only a starting point. At this stage, students can be simply considered ready to commence formal studies, and their readiness to cope with tertiary study needs to be judged against a range of contributing factors other than English language proficiency. Students who attain the minimum cut-off English language scores, and thus gain direct entry on this basis, often mistakenly believe that they possess the perquisite linguistic resources to complete their studies. This belief is sometimes reflected by their lecturers (Arkoudis, 2008). The gap between students' expectations of the language proficiency needed for academic success and integration into the academic community (as evidenced by their language proficiency score) and the reality of the 'complex academic language skills required in the university classroom' has been highlighted by Arkoudis \& Starfield (2007, p. 13).

As an alternative to meeting English language proficiency requirements on a standardized test, many universities now offer pathway programs which are designed for a particular receiving course, and have fixed exit scores, thus focusing on achievement, as opposed to proficiency alone. According to Murray and O'Loughlin (2007, p. 10), 'it can be argued the preparatory programs that allow for direct entry are meeting the needs of students entering their main course through a more comprehensive development of English language and academic preparation skills required as opposed to simply gaining a test score minimum'. Cummins and Man Yee-Fun (2007, p. 801) noted that 'acquiring academic language is challenging for all students' and that North American studies have repeatedly shown that English language learners 'require at least 5 years of exposure to academic English to catch up to native-speaker norms'. Other studies have found that commencing international students also struggle with the broader language-related issues, such as academic literacy and conventions, taking an active part in tutorials and group work (Braine, 2002). There are inherent challenges in generally becoming accustomed to 
academic life in the host country, particularly for students studying on postgraduate courses. According to Myles \& Cheng (2003, p. 248) the greatest hurdle for many students is: ...to become acculturated into a new academic and cultural community. Graduate students, in particular, feel intense pressure to succeed because many of them have scholarships and/or jobs in their native country to which they will return.

Some international students also seek to embrace an intercultural life. Although they want to have regular contact with local (Australian) students, recent figures released by Australian Education International (AEI) suggest that integration between international and local students on Australian campuses is less than optimal. Only $57 \%$ of international higher education students are satisfied with their contact with Australians (AEI, 2008, p. 5).

Communication across cultures is also integral to the successful completion of academic tasks at university. While the integration of local and overseas students on campus has for many years been the focus of much discussion (Volet \& Ang, 1998; Rowbotham, 2008), there are also inherent challenges involved in working within culturally mixed groups, a situation which is becoming increasingly common in Australian universities, as the range of diverse cultures represented expands. Recently-arrived students in particular tend to form 'clusters' (Ward \& Kennedy, 1993) with others from similar cultural and linguistic backgrounds, which provides them with much-needed support in the adjustment process, and can in fact raise self-esteem (AlSharideh \& Goe, 1998). However, this is frequently viewed by others as a lack of willingness to integrate. This is particularly relevant in the case of speakers of the Chinese languages or dialects, who currently make up increasing proportions of the overseas student population in Australia, a trend that is set to continue according to recent AEI monthly figures (AEI, 2009). Furthermore, they are more likely to revert to their own language than to speak English, which reduces the opportunity to practise the new language.

International students thus often suffer from a range of problems related to their adjustment to a new academic and cultural environment. Therefore, the role of preparation courses is crucial, not just in terms of developing English language skills at a macroskill level, but also in fostering among students the vital linguistic skills required for successful intercultural communication and integration into university life. Research so far has provided little insight into how students themselves value pathway courses, and whether they even understand their purpose. Conversely, the university community needs to be aware of the need to accommodate a range of cultures within the classroom, and to encourage two-way integration between local and international students to foster a more beneficial learning experience for all students, and ultimately to help them to attain the appropriate skills upon graduating.

\section{Context of the study}

There are separate minimum entry and exit scores for enrolment in the ELBC pathway course, for prospective undergraduate and postgraduate students. On completion of the ELBC, students who achieve the specified exit score set by the receiving School or Faculty will automatically gain a place in their chosen tertiary course. At the present time, the majority of those students are seeking entry to postgraduate degrees at the university, and therefore require a higher exit score than those bound for undergraduate study. The ELBC is normally taken fulltime over one semester, and each intake typically comprises a minimum of 150 students, with 
numbers increasing steadily. The course consists of four units: Academic Writing, English Communication, English for Specific Purposes and Tertiary Studies Skills. The Academic Writing unit involves a major individual assignment, called the research essay. English for Specific Purposes involves completing a group project and a joint presentation on a subject related to the students' intended tertiary degree (for example, Engineering, Health Sciences, Business). English Communication helps to develop the students' listening and speaking skills; this includes listening/note-taking and a formal presentation. Finally, Tertiary Studies Skills focuses on vocabulary and reading skills, with particular emphasis on summarising, and constructing a critical review.

During the ELBC, the students are exposed to a range of academic skills, with a particular focus on the appropriate language for each situation. The successful completion of the ELBC course is crucial to both undergraduates and postgraduates, as it is a necessary steppingstone for entry to their tertiary courses. Time is of the essence, as these students are on temporary study visas, and have work and scholarship commitments to fulfil. To date, most of the research relating to overseas students has concentrated on their progress in tertiary, rather than on pathway courses; and in relation to the latter, very little information is available from the students' perspective.

\section{Methodology}

The study documented here targeted a cohort of approximately 150 overseas students studying on the ELBC in the second semester of the year, with a view to entering tertiary studies (undergraduate or postgraduate) at the beginning of the next academic year. Ethics approval was granted, and a questionnaire was administered at the beginning of the semester to ascertain the demographic details of the cohort. At the end of the semester, volunteers were sought be interviewed about their experiences of the course. A group of 13 students agreed to take part in one-to-one interviews with the researcher to talk about their impressions of the ELBC and its perceived effectiveness in preparing them for study in Australia. The demographic details they had provided in their questionnaires were compared to those of the original cohort to determine the extent to which this small sample was representative. The students (six females and seven males) ranged in age from 24 to 35, and all but two were planning to complete postgraduate courses. They came from Brazil, Thailand, Indonesia, China, Saudi Arabia, Korea and the Sudan. A detailed profile is provided in Table 1. For the purposes of de-identification, the students were given fictitious names, and are referred to by their nationality in the data. 
Table 1

Profile of students interviewed at the time of completion of ELBC (Round one interviews)

\begin{tabular}{|c|c|c|c|c|c|c|}
\hline Pseudonym & Age & Gender & Nationality & $\begin{array}{l}\text { First } \\
\text { language }\end{array}$ & Intended course & $\begin{array}{l}\text { Length of time } \\
\text { in Australia }\end{array}$ \\
\hline$n / a$ & 24 & $\mathrm{~F}$ & Thai & Thai & PhD. Psychology & 3 months \\
\hline Jan & 26 & $\mathrm{~F}$ & Chinese & Chinese $^{a}$ & $\begin{array}{l}\text { Master of } \\
\text { Accounting }\end{array}$ & 3 months \\
\hline$A l i$ & 32 & M & $\begin{array}{l}\text { Saudi } \\
\text { Arabian }\end{array}$ & Arabic & $\begin{array}{l}\text { Postgraduate } \\
\text { Diploma, Clinical } \\
\text { Pharmacy }\end{array}$ & 1 year 9 months \\
\hline Michael & 28 & M & $\begin{array}{l}\text { Saudi } \\
\text { Arabian }\end{array}$ & Arabic & $\begin{array}{l}\text { Bachelor of } \\
\text { Nursing }\end{array}$ & 1 year 4 months \\
\hline Carl & 26 & M & Chinese & Chinese & Masters & 4 months \\
\hline Peter & 27 & M & Thai & Thai & $\begin{array}{l}\text { Postgraduate } \\
\text { Diploma, } \\
\text { Information } \\
\text { Mangagement }\end{array}$ & 3 months \\
\hline Alan & 30 & M & Indonesian & $\begin{array}{l}\text { Bahasa } \\
\text { Indonesian }\end{array}$ & $\begin{array}{l}\text { Masters in } \\
\text { Information } \\
\text { Technology }\end{array}$ & 3 months \\
\hline Jonah & 26 & M & Sudanese & Dinka & $\begin{array}{l}\text { Bachelor of } \\
\text { Education }\end{array}$ & 5 months \\
\hline Nicole & 24 & $\mathrm{~F}$ & Thai & Thai & $\begin{array}{l}\text { Postgraduate } \\
\text { Diploma, } \\
\text { Marketing }\end{array}$ & 3 months \\
\hline Millie & 23 & $\mathrm{~F}$ & Indonesian & Indonesian & $\begin{array}{l}\text { Postgraduate } \\
\text { Diploma, } \\
\text { Information } \\
\text { Systems }\end{array}$ & 3 months \\
\hline Andy & 31 & M & Brazilian & Portuguese & $\begin{array}{l}\text { Diploma in } \\
\text { Education }\end{array}$ & 4 years \\
\hline Oki & 35 & $\mathrm{~F}$ & Korean & Korean & Masters in Public & 3 months \\
\hline
\end{tabular}




\begin{tabular}{lllllll}
\hline & & & & & Health \\
Oni & 27 & F & Thai & Thai & Masters & 5 months
\end{tabular}

${ }^{a}$ First language as reported by the informants.

The interview format was chosen in order to explore the experiences and perceptions of the students in detail; this was an alternative to focus groups due to the potential sensitive nature of some questioning (and responses) about other participants. The interviews were semistructured, using Patton's (2002) categories as the general interview guide. The same questions were given to each student to ensure consistency. The researcher asked for information on specific core aspects of the course, and sought clarification where appropriate. The first round of one-to-one interviews was conducted upon completion of the ELBC, when the course results had been finalised. Each interview lasted approximately 20 minutes and was audiotaped with the students' consent and later transcribed verbatim. The transcriptions were then coded systematically according to emerging and recurring themes. At the time of the first round of interviews, however, the students had not yet begun their tertiary studies, and therefore had possibly not fully integrated into student life at the university.

The second round of interviews was conducted with the same group of students approximately eight months later, when they had completed at least one full semester of tertiary studies. With the benefit of time and distance, and having experienced life in a tertiary institution, the interviews provided an opportunity for the students to reflect on the course, particularly in relation to their current studies. With the exception of one student who had to return to Brazil for family reasons and who therefore did not take up his offer of study in his tertiary course at the university, all of the original 13 students returned to take part in the second round of interviews. The students were once again interviewed individually about their impressions of their tertiary course and how the ELBC had helped to prepare them for their studies. The themes identified in the first round interviews were elaborated in the second round, where the interviews generally lasted about 30 minutes. Those themes occurring most commonly in the interviews were interpreted in the light of the relevant literature.

\section{Results and Discussion}

According to their responses in the first round of interviews (on completion of the ELBC), the problems experienced by the students can be broadly divided into three categories; English language skills, academic English skills (for example, doing formal presentations, referencing) and intercultural communication. More specifically, the following were identified as areas of concern for the students: having too many speakers of Chinese languages, formal presentations, group discussions, research methods, the disparity of English proficiency levels, academic English skills, transition to university life in Australia, intercultural communication, critical thinking and student expectations. However, the most urgent need from the students' perspective was to improve their English language skills in the most efficient way possible, to enable them to cope with their assigned tasks. 
In the second round (interviews with the students following their first semester of tertiary study), according to the students' responses, the following were classified as areas of concern: lecturers' expectations of students' English levels, students' own impressions of their English language levels, lecturers' and students' accents, listening skills, access to 'local' knowledge, integration of local and international students, taking part in tutorials and coping strategies. As with the first round of interviews, the students' main priority was to master the language well enough to cope with their academic tasks, but this time, they also saw the successful integration with local students and being able to fully participate in in-class and out-of-class activities as being an integral part of their academic success.

The students' comments are summarised in the discussion that follows, and are broadly categorized into the following: oral communication (informal, when undertaking joint projects), group discussions (where participation is graded), intercultural communication (across a range of aspects of campus life), academic language skills, critical thinking, local knowledge and coping strategies. It should be noted that the nature of the experience for the students varied, depending on whether they were interacting with other international students (in ELBC) or with local English speaking students (in their tertiary programs). Documented here also are comments on the efficacy of the ELBC.

\subsection{Oral communication (informal)}

The issue of oral proficiency, including pronunciation, seemed to be one of the main areas of concern in terms of language for this cohort, a finding supported by Myles \& Cheng $(2003,255)$ in their study of graduate NNS students in Canada. Approximately half of the students enrolled in the ELBC spoke a Chinese language or dialect. This meant that each class had to have a substantial number of Chinese speakers. This caused a number of problems for some of the interviewees, particularly in relation to group work.

Several students commented that the Chinese tended not only to team up together for group discussion, but to speak in their own language when working together. This caused enormous problems in the ESP unit, where students were grouped to work on a joint project where the topic was related to their intended tertiary discipline.

as we can see the majority of students come from one country - China, and they usually hang around together in you know, small clusters, and they end up like speaking their own language...(Andy, Brazilian male)

When asked if there should be more speaking practice, several students commented on the lack of opportunity to speak English, not just in informal discussions in class, but also when working independently on group projects:

When they talk together same country, they talk the same language [Chinese] but when we have to talk in a group, we always told them "English please" because we don't understand you. (Nicole, Thai female). 
Yeh, I have to interrupt them - "Speak in English, not speak in Chinese". Like that, it is be better if group member, for example, three - one from Indonesia, another from Thailand, another from Chinese. (Alan, Indonesian male).

There were three issues at stake here; firstly for all students there was a need to develop their English skills and speaking practice in particular, such as taking part in group discussions in class, where English was the only common language. In their previous educational experience, many students had had a considerable amount of exposure to reading and writing skills in English, but far less opportunity to speak and listen to English. Unfortunately many were relying on the sixteen hours per week (over 4 units) of face-to-face class contact during the course to provide them with the skills they needed to cope in a university setting. This expectation was unrealistic (in terms of speaking and listening in particular), especially as most of them did not live in an English speaking environment, and were 'too busy studying' to listen to the radio or watch $\mathrm{TV}$, or generally engage in activities which would give them the opportunity to speak and listen in English outside class. Birrell (2006, p. 62) noted that NNS students who restrict their social life to their co-nationals, where they predominantly speak in their home language, find that their spoken English may not improve.

Secondly, and of more concern, was the fact that in formal groups where students were doing joint projects, the Chinese speakers tended to use their own language most of the time, to the obvious exclusion of the others. While this may have provided them with the opportunity to explain concepts and derive meaning from complex processes, forming 'clusters' from the same language/cultural background (Ward \& Kennedy, 1993) and providing the 'comfort zone' (Volet $\&$ Tan-Quigley, 1995) they needed, the consequences of such activities could be detrimental to the other students, both in terms of group cohesion and loss of valuable input. Such behaviour may even be resented by other group members.

Finally, and very importantly, where group assignments are concerned, in most cases equal marks are awarded to all members and so this puts enormous pressure on those students who feel their input is not used or valued, and the reality is that the ELBC is, by necessity, assessment driven. This situation was not reported as being problematic once the students began their tertiary studies, probably because there was a greater mix of nationalities in the university in general than in the ELBC, and the student cohort comprised local as well as international students.

\subsection{Formal Presentations}

In relation to the ELBC requirement to do both individual and group presentations, most of the students interviewed felt that this exercise was valuable, not only in terms of becoming familiarised with the protocol of doing formal presentations, but in terms of developing much needed confidence in speaking before a group, particularly in a second language. However, one student recommended more informal presentations in class, even if they were shorter than the formal presentations. 
I think we should have - we could practice more presentations in class - wouldn't necessarily, wouldn't need to be bigger presentations covering a big topic, but just small presentations so the students could get confident..,(Andy, Brazilian male).

When asked about the formal presentation conducted as part of the English Communication unit, others thought that it helped to develop their confidence:

The presentation was useful because I always shy in front of a group. But that helps me a lot. Anyway I practice a lot, too, because I was really shy.

(Oki, Korean female).

In addition to developing their confidence in speaking in front of groups of people, the students generally felt that the process of learning how to structure a presentation was very useful later on when they came to their tertiary studies, and one reported referring to her ELBC course notes for this purpose.

\subsection{Group Discussions}

In the ELBC, some students emphasised the importance of group discussions for encouraging students, Asians in particular, to speak up:

Lecturers need to encourage students to open their mouths. Because most of Asian students are sometimes too shy to open their mouths. You know sometimes when I am studying in the classroom, I really want to say something, but I am too shy.

(Jan, Chinese female).

While shyness may indeed be an impediment to fruitful participation in group discussion, this may not be the only stumbling block; some students also reported difficulty participating in tutorial groups once they proceeded to their tertiary studies, simply because they were scared of not being understood:

Actually the first time I afraid, because I know that I can't speak English properly and maybe they speak better than me, so I think "What if I speak, and they didn't understand me, or maybe I answer the wrong answer?" I am afraid like that. (Millie, Indonesian female).

And also we have to speak slow and clearly - try to, you know pronounce correctly otherwise they don't know what I'm talking about. That's a very worrying part for me. (Nicole, Thai female).

Such concerns were echoed by another student:

Sometimes I would like to answer, but I shy, because my accent, you know what I mean. I am afraid that the lecturer or the classmates will not understand my answer so I just keep silence. (Oni, Thai female). 
Generally, the students interviewed reported being much more self conscious about their speaking ability in their tertiary course where more native speakers (NS) were involved, than in the ELBC, where all of the students were non native speakers (NNS). Several reported the need to 'be brave' and 'have courage', indicating that they had to make a concerted effort to overcome their inhibitions about their speaking ability while they were among native speakers. Failure to do so would result in them being denied the opportunity to participate in a meaningful way.

On the other hand, self-perceptions of English language deficiencies can have much more far-reaching effects. One student felt that she was often ignored by the other students, simply because she was being judged by the perceived deficiencies in her language ability:

Once if I improve my English maybe I can get over that......

...... so if I speak like bad pronunciation or childish words because I cannot - put together, even though I can read, it's not really my words when I express my opinion: it can not combine with my speech so..that's the first impression that they can get. Once they know each other then maybe, it's a different story, but in each course, English is very important. (Oki, Korean female).

In her view, her peers did not recognize her valuable knowledge of the discipline area because she could not clearly articulate the finer points during the discussion. The students interviewed in this study also wanted to take a more active part in tutorial discussions, but frequently found that they needed time to access the correct language, while the Australian students were able to articulate ideas promptly:

Uh, I think because about critical thinking, and my very slow that Australian, when lecturer asks, the Australian just come out with the answers, something like that. We have - we need time to think about it and try to express it out. Sometimes I want to say it out but I don't know how to pick the word, what kind of sentence I have to tell, something like that. (Peter, Thai male).

I think the most difficult is about discussion part. Yeh, because we have tutorial and lecture, right? For tutorial we have to - every unit we have to discuss, but as I told you we don't know sometimes and uh, yeh, it is very difficult for me. (Oni, Thai female).

In the latter case, the student may have lacked both the language and the knowledge to be able to contribute in tutorial discussions, which are an important part of tertiary studies.

Students also reported having difficulty understanding accents. Several of the students who participated in this study noted that it takes approximately two weeks to get accustomed to each new lecturer's accent. They also found that lecturers frequently spoke too fast:

The first time the lecture was quite difficult when I started, maybe the first two weeks, and then I can get used to it.

What did you find difficult about it - was it accents, or technical language? (Researcher)

It was accents, and the speed. (Oki, Korean female)

Yeh, well the first time it wasn't OK for me because sometime the lecturer they say it very fast, and not clear enough. (Alex, Indonesian male). 
Yeh, it's good, but I think at the beginning of the semester why I feel a little difficult is that I still couldn't clearly understand the lecturers, but after one or two weeks later I used to the lecturer's accent.

The same lecturers all the time, was it? (Researcher)

Yes, same lecturer, but I feel confused. When you..such as at the beginning of this semester we changed another lecturer. I feel at the first one or two weeks, I still couldn't used ..clear understand. But after two weeks, no problem. Maybe I still need to practice. (Jan, Chinese female).

This student also referred to problems associated with varieties of English-speaking accents, as it is not unusual for lecturers themselves to be non-native speakers of English. She commented:

Like in business law, the lecturer come from Malaysia and his English is - at first we need to listen carefully and carefully. After the course I often feel very tired. But when we get used to it, we can understand. (Jan, Chinese female).

The students also reported that some lecturers' accents are easier to understand than others. For example,

Based on my experience in CBS, only several teacher pronunciation is a little bit different, I mean hard to catch. Other teacher pronunciation is very clear, and very good. (Carl, Chinese male)

When asked what the greatest challenge was for him when he started his tertiary course, one student commented that the accents of both the lecturers and the students created the most difficulty:

Well it was, you know the lecturer was going very fast.

Speaking fast, or covering a lot of content? (Researcher)

Both. You know, and before you get familiar to the guys with you in the lecture, or the tutorial and you mainly feel, to get used to Australian accent, mainly, because some of them they use a very difficult accent, you can't immediately catch what they say - you can understand what they mean, but you can't catch all the words they speak.

(Michael, Saudi male).

The accents of the local (Australian) students also caused considerable difficulty. One student indicated her desire to integrate with her local peers, but felt the she could not be accepted by them until she could speak with a similar accent.

I found that if I speak with Australian students at the first time, they feel us weird. Like you have a different accent, so I have to try more harder, to like they accept me. (Millie, Indonesian female).

Another wanted to be able to communicate on a social level with her local student counterparts, but found it difficult to make friends with them because of her perceived deficiencies in her own oral language skills:

Sometimes I feel - what do you say, I have not confidence about my speaking. Maybe I am a little afraid to chat with them. .Mm it's very difficult to make friends. I think maybe the problem is the language. (Jan, Chinese female). 
Therefore for these students, a range of linguistic skills was seen as being paramount to successful communication and integration with their peers.

\subsection{Intercultural communication}

The issue of working on a joint project for equal marks within a group is often fraught with difficulties; however the inherent problems are compounded when people with diverse cultural backgrounds, especially strangers, are put together. Most students interviewed found it challenging but useful, while one (African) student encountered an insurmountable problem in the early stages of his group project in the ELBC. While his command of English and his knowledge of the subject matter were very good, his pronunciation seemed to be problematic for the rest of the group; as a result, his ideas were systematically dismissed as being of no value. He was eventually moved to a different class where he teamed up with another student, and together they worked well as a pair. Despite having to start all over again two weeks into the course, the problems had been so serious, that in the end he was happy to move, and was grateful to the course coordinator for initiating the appropriate action. He highlighted the need for intercultural awareness in a course of this kind.

That is so, yes, in fact administration is really sensitive about the problems and in fact it is not easy, I admit it is not easy to deal with people from different backgrounds. The other person might be coming from China, and he thinks he knows English, maybe others may be coming from Indonesia or something like that and people may not know the English I have and the pronunciation is different. The other ways cultures are different in class. Maybe Bridging is very wide in a sense and Bridging needs to cover - it needs at least somebody who is (inaudible) in administration to deal with such problems. I took it as one of the (inaudible) of administration and they solved my problems. (Jonah, Sudanese male)

This issue also highlighted the need for lecturers and course coordinators to be sensitive to crosscultural clashes, and to intervene in a timely fashion.

Other students felt that mixing with people from different backgrounds in the ELBC would help to prepare them for their tertiary studies:

..... from the social, and I learned how to make friends so I know many people from many countries, even backgrounds, so I know how to ...communicate, yes, because some people from different countries have a different thinking way as me - so that's different, so I learn how to talk with them..........No, it's very hard..........

Sometimes because like I don't know how it is in their culture, but it's very different with my culture. (Millie, Indonesian female).

One Chinese student reported no difficulties within his group, but attributed this largely to the fact that the group members had similar, if not the same cultural backgrounds: 
I think our group is a very good group. We seldom have trouble to ask people to get together. (Carl, Chinese male)

When asked about the issue of working with people from other cultures, he responded:

Yes, because in our group member, only have three, we can see three cultures, China, Malaysia and Thai. All these country, the culture background is very similar. So I didn't find any challenge things to communicate or something with them, and you know $K_{-}$ and $T_{\perp}$, [naming two Thai students]- their parents all Chinese, so because they have a part-Chinese background, so it is very easy for us to communicate.

This resonates with research which indicates that establishing strong relationships with others from similar cultural backgrounds can have a positive effect on the personal adjustment of international students (Al-Sharideh \& Goe, 1998). On the other hand, the same student expressed his concern about having to face anticipated difficulties in his tertiary course, as he was able to quote problems encountered by a friend. He seemed to view the ELBC as a sort of training ground for future challenges.

...but I am not very lucky I didn't find any problem I don't know how deal with - that's also a problem. Not like other groups, they have many different problems they learn how to deal with, learn how to communicate. My friend in tertiary now has a very, very serious problem in group meeting. They waste a long time to communicate - not focus on working, focus on communicate what time we have a meet and what about a task of every meeting. They spend time on this, not only focus on work. And I worry about that in tertiary. (Carl, Chinese male.)

This notion was reflected in the comments of a female Chinese student who valued the opportunity to communicate with students from different backgrounds. She compared her situation with that of her housemates who went straight into Masters Degree courses and who missed out on such opportunities, and just studied hard day and night, returning home exhausted.

While studying in their tertiary courses, however, the experience was less positive, as the second round of interviews revealed. The South-East Asian students interviewed in this study all expressed a strong desire to integrate with the local Australian students. They desperately wanted to be accepted by the 'locals' and they also saw this possibility as an opportunity to improve their English skills, and in particular, to learn to speak with Australian accents and to find out more about Australian 'ways of thinking'. However, from the perspective of the international students interviewed, a number of barriers impeded the successful integration of local and international students. The first was that many found that local students often had parttime jobs and therefore were not available to get together on campus outside class hours. The need to seek paid employment is indeed a reality nowadays with limited financial support for tertiary students; however very few of the international students interviewed had jobs. The second factor was that several international students perceived their 'language barrier' to be the main problem, adding that other international students whose first language was English (for example, Americans, Canadians) were in a different situation, and therefore did not experience the same problems. Therefore, they saw the language factor as the most significant impediment for international students. The third and most complex factor was described as a 'way of thinking' by a Korean student, who was doing a Master of Public Health degree. Despite having a solid background in her chosen field, she was acutely aware of her inability to communicate 
with Australian students in tutorials, and felt inadequate in terms of being able to articulate more abstract concepts, such as describing her approach to tackling a problem or dealing with a topic.

In the tertiary courses in general, there seemed to be insufficient emphasis on encouraging positive integration between the various cultures. One student noted that sometimes the lecturers actively helped to ensure a multicultural mix in the groups, while others simply indicated to the students that:

We need multiculture in the group or something like that. (Peter, Thai male).

On the other hand, one student reported an incident where she was in a mixed nationality group, and the lecturer was completely unaware of how she was treated within the group:

The lecturer ask us to do what kind of factors influence demand of health care, and I mentioned outbreak of disease or new technology; those things, and the students they didn't listen what I said. They're just bothered because my speaking was made slow, or accent; I don't know why, but they, when the lecturer asked us what we discussed and they dropped my comments and talk about what they think, right, what they did. And the lecturer asked the other group. The other group mentioned what I suggested to them and the lecturer said to them "you know you had a good point". But they didn't mention about but their attitude was slightly changed maybe, what they do. (Oki, Korean female)

This was one of three separate incidents reported by the same student (one of which she described as 'shameful') where international students in mixed groups were deliberately excluded. Incidents such as this demonstrate the acute need for cross-cultural sensitivity on the part of lecturers and students, and for active intervention where and when needed. It also highlights the need to look beyond the apparent 'deficit' in oral expression, and to acknowledge the potential value in the contribution that international students can offer.

Outside class, similar problems were experienced, even under the arm of the university's 'Aussie Buddy' program which was designed to match up local and overseas students in order to facilitate a cross-cultural exchange outside class time. Only one student in this study reported accessing the program, but she found that 'if you don't approach, they don't approach', so it required a lot of effort on her part. Therefore for her at least, it wasn't as successful as she would have liked.

In most cases, the students felt that they could not fully integrate into the (tertiary) student body until they were satisfied that their English proficiency (particularly in relation to oral expression) had reached a certain point, regardless of their knowledge of the subject matter.

\subsection{Academic language skills}

The ELBC was seen as a valuable provider of language-related academic skills (for example, acknowledging sources, referencing conventions, academic style and register) over and above the technical aspects of the language. One Chinese student, while studying in the pathway course, compared her situation with that of her housemates, all Chinese, and all of whom had achieved the minimum cut-off scores on IELTS to enable them to proceed directly to their tertiary course.

My housemates - I live with three girls and they are all reading the Master of Accounting. They have to do reading, essays and the teacher ask them to do referencing, 
but now they didn't read the Bridging Course, so that have to spend a lot of time about how to do reference. (Jan, Chinese female)

In retrospect, she affirmed that learning how to use referencing conventions was a crucial skill for tertiary studies, putting her at an advantage over those who had not undertaken the pathway course.

Because I think the Bridging Course is a big help, especially the reference or when I am doing a big assignment, a major assignment; the most important part is the reference. Because I remember a group working, one of my friends come from Hong Kong, and he did not attend the Bridging Course, he went direct to study in tertiary, didn't know how to do the reference, but at this time I also tell him to do it. The lecturer will.. and the lecturer told us this is important part; if we didn't do it well he will deduct marks. (Jan, Chinese female).

Many of the students came to the ELBC with the expectation that it was only going to teach them English language skills, since the lack of English language competency was the single factor that determined their need to do this course in the first place. However, many were surprised to learn that preparing for their tertiary courses at the university entailed much more.

I don't want to think Bridging. I try to get more score in ..I take TOEFL - I want to try hard to pass - I don't want to take Bridging, but can't, my TOEFL is not enough, so I have to take Bridging. At the first time, I think Bridging teach how to learn English, grammar, something like that, but actually it's very different - it's just like how to make research. (Millie, Indonesian female).

Actually when I started Bridging, I didn't expect to get subjects, I just imagine what just language - language communication, since I get in here, I think the Bridging course is quite beneficial, the way I taught by the lecturer is good, and also the curriculum, like survey things, writing my essay, critical review, that whole thing is beneficial for my tertiary. (Oki, Korean female).

\subsection{Critical thinking}

The critical review is a key component of the Tertiary Study Skills (TSS) unit. It involves a number of skills, including summarizing, analysing and critiquing articles on contemporary topics. The approach to critical thinking in the ELBC was considered very challenging by most, and was reflected in the comments of some of the students interviewed:

Another thing is critical review. We are, in fact I think most of the Asian students are always.. how do you say, just..such as an article - if this article is written by a famous people or an expert, then we have to trust it without any challenge, but I learn from Bridging Course we can challenge if we find many mistakes or find some benefit from article, but in China the teacher told me some things were right, without any wrong, they said.' (Jan, Chinese female)

Another thing is the critical review, also it gave students the ability to think about the arguments and debatable issues, or something like that and in their mainstreams are 
important issues. These two subjects were very, very important for me, and this is the first time I have studied such materials. (Ali, Saudi male).

There was general agreement among the students interviewed that the critical review had proven very useful for tertiary studies. Although traditionally ELBC students find this one of the most difficult components of the course, the study found unanimous support for the critical review, even though the idea of evaluating the work of published authors and thinking independently still proved challenging for many. Retrospectively, the students regarded critical thinking as a very useful skill in helping them to become independent learners when they proceeded to tertiary studies.

\subsection{Local knowledge}

Another difficulty which did not become apparent until the students entered their tertiary course when attempting to process lecture content is the use of what is termed 'local' knowledge - contextual references to facts which are assumed to be known by the students, but which may not be familiar to overseas students. This difficulty was noted by Chalmers and Volet (1997, p. 91) and Hartley (2003, p. 55). Some of the students in the current study were conscious of their lack of such knowledge. They also saw this as an impediment when it came to completing some of their study tasks. One student who had been in Australia for two years indicated that when other students spoke of events which happened prior to her arrival, she had no idea what it was all about.

'Is it important to know what's going on here?' (Researcher)

'I think - if you know, it's good for you; it's more advantage'.

'Does that help your academic work or is it because you are more accepted in groups if you can discuss current things?' (Researcher)

'I think both, because in the assignment group we need to talk about that one as well. Also when we get together each other whatever assignment or talking or lifestyle - I think it's quite good if you know something around here, otherwise no-one talk. And then you just keep quiet. And then - no relationship.' (Nicole, Thai female)

'Like it's difficult for me, because we have to discuss a lot. About some issues like just in Australia so we don't know, we don't have any idea.'

'You don't have local knowledge?' (Researcher)

'Yes, especially like about car or beer, I mean the lifestyle here, we don't have any idea about that, so just keep quiet'. (Oni, Thai female).

Although 'local' knowledge may refer to anything from key course information to incidental facts, it is evident from these interviews that international students want to know more about what is going on around them so that they can successfully complete the tasks required of them and at the same time, feel they can contribute to general discussions. It is therefore important that lecturers and students try not to assume local knowledge which may exclude overseas students. Typically, students on the ELBC tend not to read newspapers or listen to news stories, lamenting the fact that they were too busy with assignments, and despite prompting 
from lecturers, do not see this as a vital part of their overall integration into (academic) life in Australia.

\subsection{Coping Strategies}

Despite the enormity of the task of adjusting to a very different academic and social culture, several of the students showed great resourcefulness in finding ways to cope with their learning situation. For example, many tried to do as much reading on a particular topic before class so that they could follow the content more easily.

'Uh, well, if we prepare before we join the lectures, it's easy....'

'By reading... you know, going through what do you call it - the outline, attending the tutorial and accessing the point before you come to - prepare yourself before you join the lecture, so that it makes everything easy for you and clear.' (Michael, Saudi male).

Some students reported accessing a range of support classes (for example, study skills, computer skills, referencing or research skills) within the university, either on the advice of friends, or from information provided by the university website. One Chinese student was cognizant of the need to avoid plagiarism, and developed strategies to record his references electronically, noting that random referencing checks take place. He also shared these skills with a friend who was having difficulty in this regard.

Generally, the international students reported a reluctance to speak to lecturers if they had a problem, preferring to consult friends first. Many of the students had also formed informal study groups with other international students from the same disciplines, and related the benefits of working collaboratively:

'Yes, even when the presentation we practice before together we can critique the others say, what we have to improve" (Millie, Indonesian female).

The students in this study seemed to find it easier to make friends with other international students than with Australian students. In particular, they seemed to be keen to form friendships with international students whose command of the English language was good, for example, one student was very happy to make some friends from Kenya, because she felt that she could learn from them.

Strategies such as those referred to above are, of course, commonly used by all students, but with the added problems caused by a language difficulty among international students, these activities require considerable initiative on their part.

\subsection{Overall reflections from students studying in their tertiary courses}

On reflection, the ELBC was generally regarded as a valuable preparation for tertiary studies. However, the informants noted a number of areas for improvement. Firstly, the title of the course (English Language Bridging Course) seems to have misled many into thinking that they would be provided with the more mechanical skills of the language, such as vocabulary and 
grammar. In fact, by default it was the fact that they hadn't yet reached an appropriate level of English proficiency that placed them in the course in the first instance, although some students elect to take on the course on recommendation from friends and family members. Ironically, in the quest to prepare the students for their future studies, the rudimentary skills of the language are frequently omitted by some course teachers, as they simply have not got the time to deal with basic language skills, since the course itself is already very intensive.

Secondly, there was an evident disparity in the English language levels of the students in the ELBC, partly because of the fact that there is no streaming with regard to whether the students are intending to study in undergraduate or postgraduate courses. This caused resentment and frustration among many students, who felt that progress was slowed down in favour of the weaker students. To compound matters, in the ESP unit, students are normally grouped by discipline, rather than by level, which means that for some, there is less incentive to do well on the group projects, which attract equal marks for all. This creates problems of equity, and frequently leads to frustration among highly-motivated students, or those who require a higher score in order to proceed to their tertiary degree.

Assumptions were also made by tertiary lecturers regarding the varying skill levels of the students, not just in terms of language levels, but also in relation to a range of other areas, such as Information Communications Technology (ICT), research methods and the expectations of the relationship between lecturers and students. For example, the frequency of contact between the $\mathrm{PhD}$ student and her supervisor was much less than she had anticipated. Other students expressed a desire to have more one-to-one contact with lecturers (as had been the case in the ELBC) but found that in most cases, their lecturers were part-time members of staff, and therefore were not often available outside of class time. Although email contact is regularly used, some students indicated that they needed face-to-face contact. For many NNS, this personal contact facilitates ease of communication and minimizes the incidence of misunderstanding.

A comparison between the two sets of interviews revealed several very important aspects of the students' perspectives on their course. Firstly, the students were very keen and willing to return and relate their experiences through the second round of interviews; their confidence in their ability to communicate orally had increased significantly. This was supported by the fact that in every case, the second round interviews lasted longer than the first. Secondly, the students' perceptions of the course from the first round of interviews seemed to focus on the challenging nature of the tasks they had to accomplish and the overwhelming nature of life on campus for a recently-arrived student. However, the second round of interviews revealed a retrospective appreciation of those same tasks, and an understanding of how useful they were, which only became apparent once they applied them in their tertiary studies. Taken together, the interviews revealed the important role that pathway courses play in helping recently-arrived overseas students to make the crucial transition in adjusting to the myriad aspects of life on campus in a western university.

\section{Conclusion and recommendations}

This study revealed that while generally the students interviewed saw their pathway program as a very useful starting point for launching into tertiary studies, they were still facing many challenges, most of them either directly or indirectly related to English language 
proficiency. On one level, the students' language skills seemed to have improved over the semester in the ELBC, and they were much more confident in their ability to deal with the basic tasks required of them, which included a range of study skills that they would be required to master over the course of their tertiary studies. On another level, the students still had a number of language issues to deal with; for example, coping with a range of accents, both among NS local students and lecturers. To compound the problem, many of the lecturers were themselves NNS, and all specialized in subject areas, rather than in English as a Second Language (ESL), and therefore would not necessarily be mindful of the specific language difficulties faced by students from varying language backgrounds. In addition, the process of adjusting to the university culture in general posed many difficulties: for example, having the opportunity to contribute in a meaningful way during class or group discussions. The resounding message from the students related not only to the difficulties in expressing themselves orally, but to issues surrounding this: for example, sheer frustration at not being able to articulate sophisticated ideas or abstract concepts readily, as they would in their first language; needing to resort to their own language in order to gain moral support; and not being considered capable of making worthwhile contributions, because they were perceived as being 'different'. Coupled with this was the overwhelming desire to integrate and belong, and to feel valued as members of a group.

One important aspect of the ELBC as demonstrated by this particular cohort is that rather than choosing to take the pathway program, they were required to undertake it by virtue of the fact that they had not acquired the prerequisite English language skills to enter their tertiary course. Yet in completing the course, they not only underwent a period of adjustment to a new academic and social culture; they also acquired a broad range of valuable academic skills, in an environment which provided a substantial degree of one-to-one academic support and supervision. Their counterparts who had proceeded directly into their tertiary courses without having to undertake such a pathway program, would have had to acquire those vital skills of their own accord.

In terms of the pathway program (ELBC), the two most urgent recommendations would seem to be: firstly, a name change that would more accurately reflect the broader approach to acquiring academic literacy, rather than simply English language proficiency; in other words, acquiring a range of linguistic skills over and above mastering the mechanics of the language itself. Secondly, it is recommended that the classes be streamed according to the students' intended level of tertiary study (undergraduate or postgraduate). Given that students intending to study on postgraduate courses require higher exit scores on completion of the course, there is more pressure on them to succeed, and the disparity between the final scores required of different students could cause problems, particularly in group projects where all group members receive equal marks.

Finally, intercultural integration is imperative if students are to fully engage in university life. This should be included in orientation programs in the first instance, but should extend to workshops and cultural orientation sessions for both staff (many of whom themselves come from a variety of cultural and linguistic backgrounds) and students on an ongoing basis, so that it becomes an integral part of student life. Successful communication between different cultural backgrounds will only work if everybody is prepared to contribute. 


\section{References}

Al-Sharideh, K., \& Goe, R. (1998). Ethnic communities within the university: an examination of factors influencing the personal adjustment of international students. Research in Higher Education, 39, 699-725.

Arkoudis, S. (2008). It’s not plain English. Campus Review. 18 (29), 6.

Arkoudis, S. \& Starfield, S. (2007). In-course language development and support: A discussion paper. Available at http://aei.gov.au/AEI/Shop/Products/Publications/Publication624

Australian Education International (AEI), (2008). 2007 Follow-up International Student Survey. Commonwealth of Australia: Canberra.

Australian Education International (AEI), (2009) Monthly Statistics, September 2009 http://aei.gov.au/AEI/MIP/Statistics/StudentEnrolmentAndVisaStatistics/2009/MonthlyS ummary_Sep09_pdf.pdf (accessed 18th November, 2009)

Birrell, B. (2006). Implications of low English standards among overseas students in Australian universities. People and Place 14 (4), 53-65.

Braine, G. (2002). Academic Literacy and the nonnative speaker graduate student. Journal of English for Academic Purposes 1, 59-68.

Chalmers, D. \& Volet, S. (1997). Common Misconceptions about Students from South-East Asia Studying in Australia. Higher Education Research \& Development 16 (1), 87 - 98.

Cummins, J. \& Man Yee Fun, E. (2007). Academic language: What is it and how do we acquire it? In J. Cummins \& C. Davison (Eds.), International Handbook of English Language Teaching (Vol 2) (pp. 797-810). Norwell, MA: Springer.

Hartley, B. (2003). Just Return for Dedicated Investment: Internationalisation, Japanese Language Teacher Education, and Students' Expectations . In Liddicoat, A., Eisenchlas, S., \& Trevaskes, S., (Eds.) Australian Perspectives on Internationalising Education. Melbourne: Language Australia.

Healy, G. (2008, September 10). High university costs fail to deter overseas students. The Australian, p. 1.

Murray D \& O'Loughlin K (2007). Pathways - Preparation and Selection: A discussion paper. Available at http://aei.gov.au/AEI/Shop/Products/Publications/Publication623 
Myles, J. \& Cheng, L. (2003). The social and cultural life of non-native English speaking international graduate students at a Canadian university. Journal of English for Academic Purposes 2, 247-263.

Patton, M. (2002). Qualitative Research \& Evaluation Methods $\left(3^{\text {rd }}\right.$ ed.). London: Sage Publications.

Rowbotham, J. (2008, September 24). Rocky road to integration. The Australian Higher Education supplement, p. 32.

Volet, S.E. \& Ang, G. (1998). Culturally Mixed Groups on International Campuses: an Opportunity for Inter-cultural Learning. Higher Education Research \& Development, 17 (1), 5-23.

Volet, S.E. \& Tan-Quigley (1995). Daring to be different: unspoken agendas in interactions between international students and general staff at university. Paper presented at the International Students Advisors Network of Australia (ISANA) Conference, Fremantle, Australia.

Ward, C.A. \& Kennedy, A. (1993). Where's the "culture" in cross-cultural transition? Comparative studies of sojourner adjustment. Journal of Cross-cultural Psychology, 24 (2), 221-249. 